\title{
Molecular Pathogenesis of Hepatocellular Carcinoma
}

\author{
Daniel Wai-Hung Ho $\mathrm{H}^{\mathrm{a}, \mathrm{b}}$ Regina Cheuk-Lam Lo ${ }^{\mathrm{a}, \mathrm{b}}$ \\ Lo-Kong Chan ${ }^{a, b}$ Irene Oi-Lin Nga,b \\ aDepartment of Pathology and bState Key Laboratory for Liver Research, The University of \\ Hong Kong, Hong Kong, SAR, China
}

\section{Key Words}

Cancer stem cells · Hepatocellular carcinoma - Molecular alterations ·

Next-generation sequencing

\begin{abstract}
The pathogenesis of hepatocellular carcinoma ( $\mathrm{HCC}$ ) is a multistep process involving the progressive accumulation of molecular alterations pinpointing different molecular and cellular events. The next-generation sequencing technology is facilitating the global and systematic evaluation of molecular landscapes in HCC. There is emerging evidence supporting the importance of cancer metabolism and tumor microenvironment in providing a favorable and supportive niche to expedite HCC development. Moreover, recent studies have identified distinct surface markers of cancer stem cell (CSC) in HCC, and they also put forward the profound involvement of altered signaling pathways and epigenetic modifications in CSCs, in addition to the concomitant drug resistance and metastasis. Taken together, multiple key genetic and non-genetic factors, as well as liver CSCs, result in the development and progression of HCC.

Copyright (C) 2016 S. Karger AG, Basel
\end{abstract}

\section{Recent Applications of Next-Generation Sequencing (NGS) Technology in Capturing Molecular Alterations in Hepatocellular Carcinoma (HCC)}

Molecular alterations at both genetic and epigenetic levels have been shown to drive hepatocarcinogenesis. The recent adoption of advanced NGS in analyzing HCC samples from 


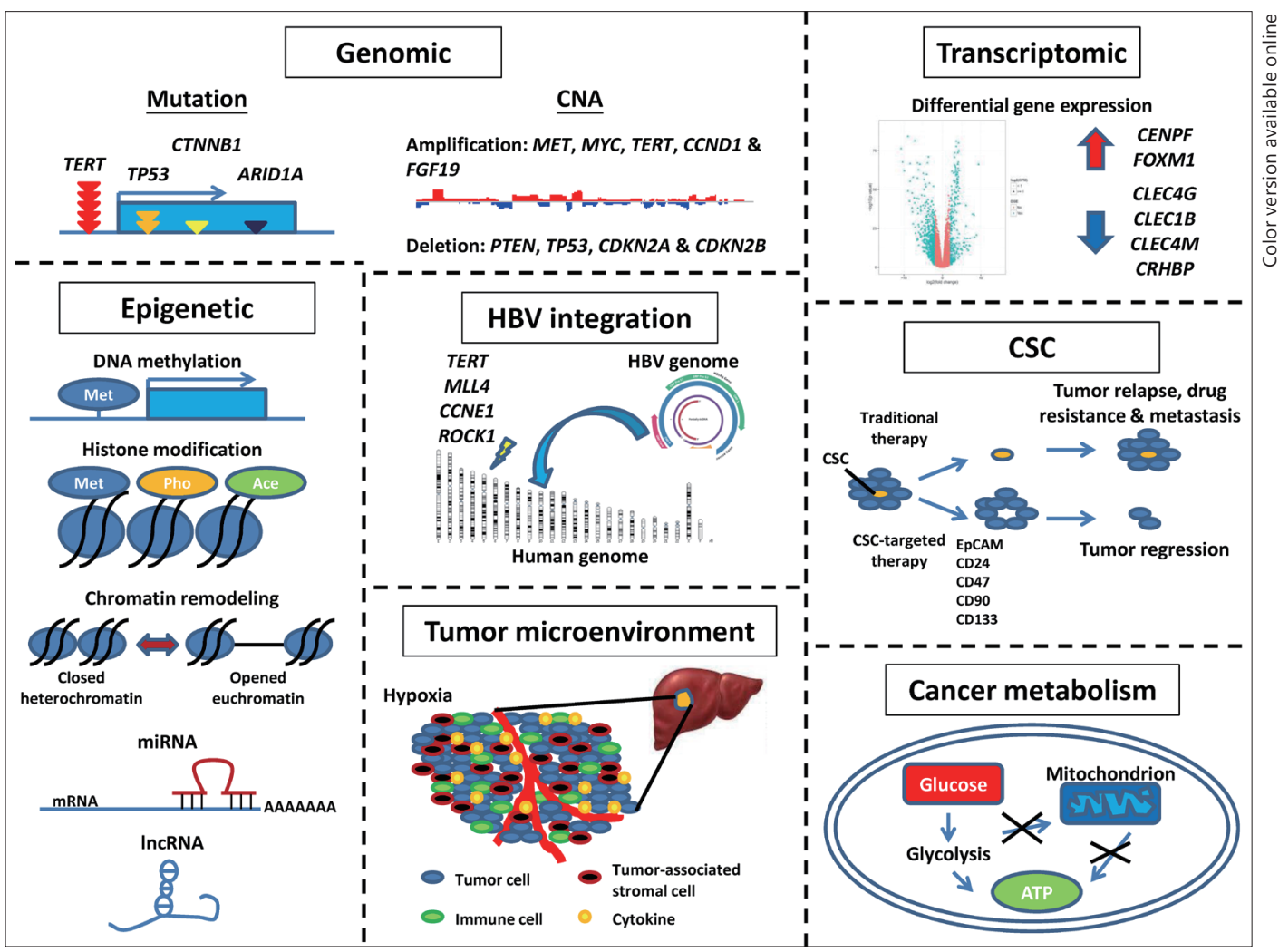

Fig. 1. Schematic overview of key events in the molecular pathogenesis of HCC.

patient enables us to revisit and explore the global molecular landscapes of HCC at multiple levels ranging from copy number alterations (CNAs) and somatic mutations at the genome level, to gene expression at transcriptome level, as well as epigenetic changes. Furthermore, the capability of NGS to unbiasedly capture all the viral integration sites provides a whole new way to understand the interplay between hepatitis B virus (HBV) and the host genome (fig. 1).

\section{Genomic Alterations}

\section{Large-Scale and Focal CNAs}

Genome instability is a key driver in human cancers including HCC, and this may result in CNAs with gain or loss in chromosomes of different extents or somatic mutations in the genomes. In the pre-NGS era, comparative genome hybridization and its array-based derivatives were commonly used to profile and uncover the global picture of chromosomal gains or losses $[1,2]$. Recently, three independent studies have evaluated CNAs by comparing the sequencing data generated by whole-genome and whole-exome sequencing in paired HCC samples [3-5]. Their results have allowed the generation of a map with better resolution highlighting the chromosome gains and losses in HCC. Specifically, they collectively show frequent large-scale gains at 1q, 5p, 6p, 8q, 17q, 20q and Xq; and losses at 1p, 4p-q, 6q, 8p, $13 p-q, 16 p-q, 17 p, 21 p-q$ and 22q. Interestingly, focal amplifications at oncogenes including MET, MYC, TERT, CCND1 and FGF19, and focal deletions at tumor suppressors including 
PTEN, TP53, CDKN2A and CDKN2B were detected. The overall findings are consistent with the previous reports using different technologies [6].

\section{Common Mutations of Protein Coding Genes}

Recently, active NGS-based genome-wide mutational screenings in HCC samples with different etiological backgrounds have been carried out worldwide [3-5, 7-13]. CTNNB1 and TP53 are the most commonly mutated genes in HCC. Mutant CTNNB1 has been shown to be the putative driver for alcoholic HCC, while the mutant TP53 is likely to be associated with HBV infection [4]. In addition to the previously documented mutant genes, these studies have further identified other putative drivers, e.g. CDKN2A, RB1, AXIN1, ARID1A, ARID1B, ARID2, NFE2L2, KEAP1, RPS6KA3, MLL, MLL3 and MLL4, to be recurrently mutated at high frequencies. These novel mutations have been suggested to play deleterious effects on their intrinsic protein function. Pathway analysis has further demonstrated their potential roles in affecting multiple facets of human cellular machinery such as deoxyribonucleic acid (DNA) repair and surveillance (TP53, CDKN2A and RB1), Wnt/ $\beta$-catenin signaling (CTNNB1 and AXIN1), chromatin remodeling ( $A R I D 1 A, A R I D 1 B$ and $A R I D 2)$, oncogenic mitogen-activated protein kinase (MAPK) signaling (RPS6KA3), oxidative stress (NFE2L2 and KEAP1), and histone modification (MLL, MLL3 and MLL4). However, how these mutants functionally cooperate amongst themselves remains to be addressed. Recently, Schulze et al. took an integrative approach to assess the somatic mutations and focal CNAs in human HCCs to look for gene targets which are frequently and significantly altered through different mechanisms [4]. They listed and reported 161 putative HCC driver genes. Further validation of these novel targets, along with the aforementioned mutant genes, on relevant HCC samples and in vivo models would significantly help to derive novel molecular insight in the realm of human HCC.

\section{TERT Promoter Mutations}

Apart from the aforementioned putative HCC drivers affecting a wide spectrum of cellular processes, emerging evidence has indicated frequent and recurrent somatic mutations in the promoter area of the TERT (telomerase reverse transcriptase) in various types of cancer $[14,15]$. The hotspot TERT promoter mutations $(-124 \mathrm{G}>\mathrm{A}$ and $-146 \mathrm{G}>\mathrm{A}$; with the numbers that denote the distance from the ATG start site) creates potential binding sites for E-twenty six/ternary complex factor transcription factors, which increase the promoter activity and transcription of TERT. As a result, a mutation screening study was undertaken in HCC to investigate the prevalence of TERT promoter mutations [16]. It was found that such mutations affected $59 \%$ of a large cohort of human HCC samples (n=305). Moreover, TERT was found to be the first gene recurrently mutated in preneoplastic lesions in cirrhosis and its promoter mutations was involved in the last step of malignant transformation from hepatocellular adenoma into HCC [16]. Subsequently, another report from the same group [17] revealed that TERT promoter mutations were highly related to the step-wise hepatocarcinogenesis, with its frequency increasing progressively from $6 \%$ in low-grade dysplastic nodules $(n=32)$, through $19 \%$ in high-grade dysplastic nodules ( $n=16)$, and which peaked at $61 \%$ in early HCCs $(n=23)$ and $42 \%$ in small and progressed HCCs $(n=17)$, respectively. It has also been suggested that TERT is the earliest somatic alteration, since mutations of 10 other recurrently mutated HCC genes are only identified in $28 \%$ of small and progressed HCCs. Somatic TERT promoter mutations are believed to be a new predictive marker in highlighting the transformation of a premalignant lesion, on a cirrhotic background, into a HCC.

\section{HBV Integration}

Among the identified etiological risk factors for HCC, which include chronic viral infections (HBV and hepatitis $\mathrm{C}$ virus), chronic alcohol consumption, and non-alcoholic fatty liver 
disease and non-alcoholic steatohepatitis, chronic HBV infection accounts for around 50\% of the cases [18]. One of the distinctive features of HBV DNA is that it can integrate into the human genome, which in turn disrupts the endogenous tumor suppressors and other regulatory genes, or enhances the activity of proto-oncogenes. The resultant enhanced survival, proliferation and reduction in apoptosis may lead to an imbalance of the overall oncogenic and tumor suppressive signals, thus supporting HCC development. In the past, biased polymerase chain reaction (PCR)-based methods were employed to detect HBV integration sites [19]. Recent studies have commonly used NGS-based methods such as whole-genome sequencing, whole-transcriptome sequencing or other derivatives [8, 20-25]. TERT, MLL4, CCNE1 and ROCK1 are frequently and recurrently affected by HBV integration. Intriguingly, a recent study has reported the frequent (23.3\%) $H B X$-LINE1 chimeric transcript resulting from HBV integration in HBV-associated HCC [23]. Such HBX-LINE1 fusion results in a long non-coding ribonucleic acid (lncRNA) and it is associated with poorer overall patient survival. HBX-LINE1 expression activates Wnt signaling through $\beta$-catenin transactivity. However, such frequent and positionally recurrent $H B x$-LINE1 fusion has not been identifiable in a number of genome-wide HBV integration surveys [8, 20-22, 24, 25], suggesting a possible difference in its actual frequency, an uneven ethnic distribution, or possibly technical artifact contamination in its detection. The reason for the discrepancy remains to be elucidated, but further verification is awaited.

\section{Epigenetic Alterations}

Epigenetic alterations are reversible modifications at the genome level without involving changes of the DNA sequence. They control the gene expression level through modulations at the gene transcription level (DNA methylation, histone modification, and chromatin remodeling) as well as post-transcriptionally through various non-coding RNAs (ncRNAs) (e.g. microRNAs [miRNAs] and lncRNAs). Existing studies focusing on the epigenetic regulation of individual genes or particular gene sets have been reviewed and summarized elsewhere [26-29]. In a global perspective, systematic array-based and more recently NGSbased studies have revealed that significant numbers of gene targets are affected by aberrant DNA methylation at the gene promoter regions, and this directly increases or decreases the downstream gene transcription activity $[6,30]$.

Recently, using advanced sequencing technologies, a number of studies have identified and characterized less well-explored ncRNAs in human HCC. In particular, Law et al. identified piR-Hep1, a new class of ncRNAs with between 26-32 nucleotides, being upregulated in nearly half of the HCC tumors that were screened. This upregulation is functionally linked to an increased proliferation rate and tumor invasiveness, likely through maintaining active AKT signaling [26]. Conversely, further analysis of the miRNome (all the miRNAs expressed in a given genome) data has highlighted the significant association of miR-1323 overexpression in cirrhosis. Mizuguchi et al. highlighted the upregulation of miR-21 and miR-34a and downregulation of miR-122 in HCC [27], suggesting the potential use of this molecular signature as a biomarker to detect HCC.

Currently, limited work has been performed to explore the role of IncRNAs in human HCC. Our group utilized a quantitative PCR-based assay to profile a subset of 88 well-annotated IncRNAs and identified a IncRNA, HOTTIP, to be frequently upregulated in HCC. HOTTIP is under the negative regulation of miR-125b, a miRNA with frequent downregulation in HCC. HOTTIP has been demonstrated to play a significant oncogenic role in HCC, possibly through the upregulation of HOXA genes [31]. Given the lack of systematic capture of epi- 
genetic regulations at multiple levels (e.g. DNA epigenetic marks, histone marks, expression of epigenetic regulators, and ncRNAs) in the same HCC sample set with defined etiological background, further global studies are awaited to gain a better understanding of how deregulation of the diverse epigenetic events collectively contributes to gene expression changes in HCC development.

\section{Transcriptomic Alterations}

Compared with the active global sequencing analysis at the genomic level, only a few NGS-based whole-transcriptomic exploratory analyses have been carried out in human HCC. They revealed the transcriptomic landscape of HCC through comparing tumors against the corresponding non-tumorous liver tissues [32-34]. Many of them had very limited sample sizes in providing a representative overview and identifying critical gene expression changes. Our group reported the use of The Cancer Genome Atlas HCC whole-transcriptome sequencing data, consisting of a relatively large sample cohort, to identify key differential gene expression patterns [32]. Apart from the dysregulations in the expression of ALG1l, SERPINA11, TMEM82, GPC3, SPINK1 and ESM1 which were reported by other studies, other genes such as CENPF and FOXM1 were found to be the top-listing upregulated genes. CENPF is an essential protein for kinetochore function and mitotic segregation, while FOXM1 is a forkhead box protein transcription factor that regulates cell cycle processes and in turn controls cell proliferation and DNA damage repair. Concurrent upregulation of these two proteins in HCC likely suggests their potential functional synergism, as recently suggested in prostate cancer. On the other hand, multiple members of the C-type lectin family (CLEC4G, CLEC1B and CLEC4M) and CRHBP (corticotropin-releasing hormone binding protein) were found to be downregulated. C-type lectins are calcium-dependent glycan binding proteins involved in adhesion, and they act as signaling receptors for immune-related processes such as inflammation and immune responses towards tumor and virally infected cells. The downregulation of C-type lectin expression may suggest its involvement in the pathogenesis of HCC. Conversely, corticotropinreleasing factor (CRF) has been shown to modulate tumor progression and angiogenesis in various cancers. Depletion of CRHBP, a member of the CRF system, may likewise be involved in hepatocarcinogenesis through similar mechanisms.

\section{Altered Cell Signaling Pathways}

The valuable information generated by various genomic, transcriptomic and epigenetic alterations provide us with a comprehensive assessment about how these changes may affect key signaling pathways supporting the development of HCC. Although the current understanding on altered signaling pathways in HCC is far from complete, emerging evidence generated by using different model systems have improved our understanding that a confined subset of cell signaling pathways may be sequentially involved in hepatocarcinogenesis and tumor progression with metastasis [35-37]. In brief, these pathways play critical roles in controlling a wide range of essential biological processes required by the tumors in maintaining survival and adapting to the microenvironmental changes which includes Wnt/ $\beta$-catenin, Notch and Hedgehog signaling pathways (differentiation and development), p53/p21 and RB1 signaling pathways (genomic stability and cell cycle regulation), EGF/EGFR, HGF/MET, IGF/IGFR, PI3K/AKT/mTOR and RAS/MAPK growth factor receptor signaling (cell proliferation and survival), VEGF/VEGFR, PDGF/PDGFR and FGF/FGFR signaling pathways (angiogen- 
esis), NFE2L2/KEAP1 signaling pathway (oxidative stress), ARID1A/ARID1B/ARID2 and MLL signaling pathways (chromatin regulation), and JAK/STAT signaling pathway (cytokine and growth factor signaling transduction).

To date, the multikinase (VEGFR, PDGFR, B-raf and C-raf) inhibitor sorafenib is the only United States Food and Drug Administration-approved molecular drug for advanced HCC with modest survival benefits due to development of drug resistance. This resistance had been suggested to be contributed to by the upregulation of oncogenic AKT activation [38] and the potential involvement of additional pathways including TGF- $\beta$-SMAD [39] and NF- $\kappa B$ [40] signaling. With the use of a liver specific p19Arf knockout mouse model, Rudalska et al. performed the first unbiased in vivo RNA interference screening for potential targets underlying sorafenib resistance [41]. They performed hydrodynamic injection of a predesigned small hairpin RNA (shRNA) library of 253 shRNAs which specifically targeted genes located in the genome with frequent focal amplification in patients with HCC and cell lines, followed by comparing the individual shRNA enrichment or depletion ratio between the sorafenib and control treated tumors by deep sequencing. MAPK14 gene, encoding p38 $\alpha$ stress response kinase, was identified to specifically maintain the active Raf-MAPK signaling cascade in phosphorylating the downstream phospho-ATF2 substrate upon sorafenib treatment. Interestingly, p38 $\alpha$ appears to play a highly specific role in conferring sorafenib resistance, as knockdown of p38 $\alpha$ did not show an observable impact on the intrahepatic tumor burden and overall survival in mice. With these data generated by advanced sequencing technologies on patient samples having well-defined clinical backgrounds, it enables the search for clinically relevant gene targets for complementing the use of sorafenib, or it opens up the design of an alternative substitute for a more personalized management for patients with HCC carrying a specific type of molecular signature.

\section{Multi-Step Molecular Pathogenesis Leading to HCC}

With efforts from studies pinpointing the multiple aspects of HCC pathogenesis, knowledge has been accumulating on the stochastic molecular alterations (as mentioned in previous sections) targeting different cancer hallmark events [42]. Traditionally, it is believed that HCC emerges from normal hepatocytes, through sequential acquisition of essential molecular alterations that empower them with cancer hallmark capabilities. It is a long and cumulative process under the continued clonal selective pressure that certain subclones of cells possessing growth and survival advantage will dynamically undergo clonal expansion. As a result, the clonal evolution of altered hepatocytes progressively transform into HCC. Recently identified findings also emphasize the importance of cancer metabolism and tumor-promoting microenvironment in augmenting the development of HCC (fig. 1). More importantly, the cancer stem cell (CSC) theory which has emerged in recent decades, together with the traditional clonal evolution model, helps to explain the underlying molecular mechanisms of HCC to a better extent, particularly in the context of tumor relapse, chemoresistance and metastasis (fig. 1).

\section{HCC and Cancer Metabolism}

The intimate relationship between tumor microenvironment and cancer metabolism has been explored in a number of studies and new data are rapidly emerging [43]. A spotlight in this area lies in the link between the hypoxic tumor microenvironment and glycolysis [44]. 
While human cells physiologically generate energy in the form of adenosine triphosphate by oxidative phosphorylation in the presence of oxygen, cancer cells preferentially adopt aerobic glycolysis as a major mechanism for energy production. This is the well-known Warburg effect [45].

In HCC, hypoxia-inducible factor (HIF)-1-induced glycolysis is associated with biological aggressiveness [46]. In 2004, correlation analysis of the expression of hypoxia marker and glycolytic enzyme, hexokinase II, in HCC suggested that HCC cells switched to glycolysis through the mediation of HIF-1 [47]. Apart from hexokinase II, hypoxia also reprograms cancer cells to glycolysis through induction of glucose transporter 1 (GLUT-1). GLUT-1 is a crucial player in the glycolytic pathway and located on the cell surface enhancing glucose uptake into the cell $[48,49]$. GLUT-1 protein expression levels have been reported to be associated with higher tumor grades, advanced tumor stages, and higher proliferative index in HCC [50]. It is also a potential therapeutic target for HCC [51]. HIF-1 co-operates with c-myc to facilitate aerobic glycolysis [52]. Other regulators of GLUT-1 include p53 [53] and the PI3K/AKT pathway [54].

Pyruvate kinase isozyme M2 (PKM2) has been an active area for research with respect to HCC glycolysis in recent years. PKM2 expression in HCCs correlates with vascular invasion and advanced tumor stages. PKM2+TRIM35- is an indicator for poorer patient survival [55]. Our group has reported the overexpression of PKM2 in human HCCs, and silencing of PKM2 inhibits HCC aerobic glycolysis, in vitro cell proliferation, as well as in vivo tumor growth and metastasis. Moreover, miR-122 is a negative regulator of PKM2 by directly interacting with the $3^{\prime}$-untranslated region of the latter [56]. Similar findings were reported by Liu et al [57]. As a crucial regulator of HCC glycolysis, several key modulators of PKM2 have been identified in recent years. PARP14 activates PKM2 through inhibition of pro-apoptotic kinase JNK1 [58]. Mineralocorticoid negatively regulates pyruvate kinase by targeting miR-388-3p [59]. Inactivation of Spry 2 fosters HCC glycolysis by activating PKM2 in AKT-overexpressing cells [60]. In addition to PKM2, our group reported the role of PIM1 in HCC glycolysis, which is overexpressed in human HCC tissues. Knockdown of PIM1 suppressed cell proliferation and invasion in vitro, as well as tumor growth and metastasis in vivo. Furthermore, PIM1 facilitates glycolysis in HCC cells possibly through AKT [61].

The identification of functional markers for HCC glycolysis would shed light on therapeutic opportunities. Specific inhibitors and monoclonal antibodies might serve as alternatives in some cases. Furthermore, other elements in the tumor microenvironment, such as cancerassociated fibroblasts and immune cells, are potentially involved in the metabolic reprogramming of HCC not limited to glycolysis. This area definitely warrants further investigations.

\section{CSCs of HCC}

CSCs or tumor-initiating cells are a subpopulation of tumor cells that possess the ability to self-renew and differentiate [62]. Moreover, CSCs confer chemo- and radio-resistance [63]. As a consequence, CSCs are believed to play a crucial role in tumor initiation and tumor relapse clinically.

In HCC, a recent comprehensive study provided insight on the origin of liver CSCs. Holszbauer et al. elegantly demonstrated that liver CSCs originated from three hepatic lineages - adult differentiated hepatocytes, hepatoblasts and adult hepatic progenitor cells [64]. Among the liver CSCs arising from these hepatic lineages, epithelial-mesenchymal transition and embryonic stem cell (ESC) related genes were found to be significantly upregulated. In particular, tumors that developed from adult hepatocyte-reprogrammed CSCs displayed the greatest number of activated ESC-related genes in which Myc ranked first on the list. Although 


\section{Liver}

liver CSCs evolving from different cells of origin can share similar CSC phenotypes, they are genetically different in terms of self-renewal through the specific modulation of signaling pathways. In view of this, there is a need to further subclassify and characterize liver CSCs.

\section{Major and Characterized Liver CSC Surface Markers}

Over the past decade, a number of liver CSC surface markers have been identified, as evidenced by the functional CSC properties. Identified liver CSC markers include epithelial cell adhesion molecule (EpCAM), CD133, CD90, CD13, CD44, CD24, CD47, OV6, GEP, and DLK1 $[65,66]$. Notably, liver CSCs can be enriched by chemotherapeutic agents; doxorubicin and fluorouracil enriched CD133+ HCC cells [67] and sorafenib enriched EpCAM+ as well as CD47+ HCC cells, to name a few $[40,68]$.

\section{Signaling Pathways Associated with CSC}

In normal hepatic progenitor cells, the Wnt/ $\beta$-catenin signaling and STAT3 signaling pathways are responsible for liver specification and liver regeneration in a strictly controlled manner [69-71]. Dysregulation of these two pathways has also been found to be associated with the maintenance of liver CSCs. With regard to the Wnt/ $\beta$-catenin signaling pathway, Mokkapati et al. reported that stabilization of $\beta$-catenin in liver stem/progenitor cells using $\beta$-catenin overexpressing transgenic mice resulted in the development of HCC with spontaneous lung metastases [72]. Its activation led to the enrichment of EpCAM+ and OV6+ liver CSCs and subsequently to cancer cell growth [73] and chemoresistance [74].

For the STAT3 signaling pathway, two independent studies deciphered the role of CD24+ CSCs in the development of HCC. Lee et al. demonstrated that CD24+ cells endowed CSC properties through the STAT3-mediated NANOG pathway [75], while Liu et al. further reported that Twist2 regulated CD24 expression by direct binding to the E-box region located on the CD24 promoter [76]. The STAT3 signaling pathway is augmented in response to proinflammatory cytokines and this may lead to tumor formation. A recent study has shown that the IL6/STAT3 signaling cascade gives rise to the enrichment of CD133+ in HCC [77]. Thus, STAT3 signaling appears to be an important pathway deregulated during early hepatocarcinogenesis. Other signaling pathways implicated in liver CSCs include sonic hedgehog signaling, Ras/Raf/MAPK signaling, the Notch pathway, PI3-K/Akt/mTOR and TGF- $\beta$ signaling. Deregulation of these cascades has been shown to result in the enrichment of CSCs, typified by various liver CSC surface markers [66].

\section{Epigenetic Regulation of CSC Expression}

Apart from the signaling cascades, there is a growing interest in the epigenetic regulation of CSC expression. Epigenetic regulators, histone deacetylase 3 and DNA methyltransferase 1 (DNMT1) have been reported in the maintenance of CSCs [78, 79]. Intriguingly, liver CSCs are generally more hypomethylated than the differentiated cancer cells [80]. It is reported that TGF- $\beta 1$ enhanced CD133+ HCC cells by inhibiting DNMT1 and DNMT3 $\beta$, which are critical in the maintenance of regional DNA methylation [81]. Moreover, treatment with a DNMT1 inhibitor induced CSC properties in an isolated liver CSC side population [82]. As far as miRNA is concerned, miR-142-3p was reported to inversely correlate with the expression of CD133 in HCC [83], whereas miR-181 expression led to the enrichment of EpCAM+ HCC cells [84].

\section{CSC and Tumor Microenvironment}

Since most HCCs develop from a chronic inflammatory background of the liver, it has been reasoned that CSCs can evolve, or their stemness properties are maintained from the interaction with the tumor microenvironment, including stromal cells and extracellular ma- 
trix, hypoxia, and immune cells [85]. Increased matrix stiffness caused by chronic inflammation is a common pathological condition occurring in HCC. Schrader et al. demonstrated that an environment with increased stiffness profoundly altered the phenotype and behavior of HCC cells in vitro. Increased matrix stiffness led to enhanced HCC cell proliferation and resistance to cisplatin treatment, whereas a soft physiological environment enriched CSC surface markers and enhance stemness gene expression (CD133, CD44, CXCR4, OCT4 and NANOG) [86]. Furthermore, elevated expression levels of proinflammatory cytokines are detected during inflammation. IL6, a cytokine secreted by tumor-associated macrophages (TAMs), has been detected in HCC samples and recently found to promote the expansion of CD44+ cells in HCCs by co-culturing CD14+ TAMs [87].

$\mathrm{NF}-\kappa \mathrm{B}$ signaling pathway is heavily implicated in the inflammatory response in the liver. Literature studies have provided hints for linking NF- $\kappa B$ from chronic liver injury to HCC upon proinflammatory cytokine stimulation [88]. This pathway has been shown to play a key role in inflammation induced hepatocarcinogenesis [88]. Given that the inflammatory milieu is a potential breeding hub for liver CSCs, there is only scarce information about the role of NF- $\mathrm{KB}$ in liver CSCs. Lo et al. reported that NF- $\mathrm{BB}$ regulated the CD47 overexpression in sorafenibresistant HCC cells and this endowed the CSC properties [40]. Recently, NF- $\kappa B$ has been shown to be associated with cancer stemness in HCC [89]. The linkage between NF- $\mathrm{BB}$ and liver CSCs appears to be a promising area of study. Besides, the emergence of three-dimensional tissue organoid system is more structurally relevant and it can recapitulate, to a greater extent, in vivo pathophysiological processes. Hans Clevers' group has successfully cultured injury induced Lgr5+ liver cells in an organoid system and subsequently delineated the Wnt signalingmediated expansion of Lgr5+ progenitor cells after liver injury [90]. As mentioned previously, since enrichment of liver CSCs partly depends on the interaction with the tumor microenvironment, the organoid system is able to resemble the in vivo conditions and tackle with the drawbacks of the commonly used two-dimensional culture system. By doing so, the picture of the tumorigenesis from the evolvement of CSCs to tumor formation may be unveiled.

\section{Liver CSCs-Therapeutic Opportunities and Applications}

Despite the emergence of various therapeutic modalities including chemotherapy, targeted therapy and radiotherapy in recent years, the efficacy in eradicating HCC is still unsatisfactory partially attributed to resistance to treatment conferred by liver CSCs. Residual liver CSCs that survive from therapeutic agents are able to initiate tumor formation and lead to tumor recurrence. Thus, targeting and eliminating liver CSCs is an appealing direction to devise further treatment options. Recent work has illustrated that sorafenib enriches EpCAM+ liver CSCs via the TSC2-AKT pathway [68]. In this context, agents that reduce Akt activity would be a potential therapeutic treatment for the elimination of EpCAM+ liver CSCs induced by sorafenib. Apart from targeting the signaling pathway, the use of monoclonal antibody targeting CSC surface markers is also a potential treatment to eradicate CSCs. As CD47+ HCC cells are enriched in sorafenib-resistant HCC cells, it has been shown that anti-CD47 monoclonal antibody can reduce liver CSCs properties and sensitize HCC cells to both conventional chemotherapeutic drugs and sorafenib treatment $[40,91]$. These encouraging findings should prompt further work to characterize CSC genes and associated targeted therapies.

\section{Conclusions}

Dissection of hepatocarcinogenesis at multiple molecular levels potentially sheds light on alternative treatment options. Identification of key molecular events and crucial signal- 
ing pathways provides insight to devise targeted therapies to treat this cancer. On the other hand, recent studies using NGS technology have facilitated the global and systematic evaluation of molecular landscapes in HCC. Emerging evidence supports the importance of cancer metabolism and tumor microenvironment in providing a favorable and supportive niche to expedite the development of HCC. Moreover, the importance of liver CSCs in HCC and their involvement of altered signaling pathways, epigenetic modifications, concomitant drug resistance and metastasis have highlighted their roles of potential targets of novel treatments. Therefore, future effective novel therapies against specific targets in HCC are anticipated, and we believe there will be better management of patients with HCC from improved treatment efficacy.

\section{Conflict of Interest}

The authors declare none.

\section{References}

1 Thorgeirsson SS, Grisham JW: Molecular pathogenesis of human hepatocellular carcinoma. Nat Genet 2002;31:339-346.

2 Kumar M, Zhao X, Wang XW: Molecular carcinogenesis of hepatocellular carcinoma and intrahepatic cholangiocarcinoma: one step closer to personalized medicine? Cell Biosci 2011;1:5.

3 Kan Z, Zheng H, Liu X, Li S, Barber TD, Gong Z, Gao H, Hao K, Willard MD, Xu J, Hauptschein R, Rejto PA, Fernandez J, Wang G, Zhang Q, Wang B, Chen R, Wang J, Lee NP, Zhou W, Lin Z, Peng Z, Yi K, Chen S, Li L, Fan X, Yang J, Ye R, Ju J, Wang K, Estrella H, Deng S, Wei P, Qiu M, Wulur IH, Liu J, Ehsani ME, Zhang C, Loboda A, Sung WK, Aggarwal A, Poon RT, Fan ST, Wang J, Hardwick J, Reinhard C, Dai H, Li Y, Luk JM, Mao M: Whole-genome sequencing identifies recurrent mutations in hepatocellular carcinoma. Genome Res 2013;23:1422-1433.

4 Schulze K, Imbeaud S, Letouzé E, Alexandrov LB, Calderaro J, Rebouissou S, Couchy G, Meiller C, Shinde J, Soysouvanh F, Calatayud AL, Pinyol R, Pelletier L, Balabaud C, Laurent A, Blanc JF, Mazzaferro V, Calvo F, Villanueva A, Nault JC, Bioulac-Sage P, Stratton MR, Llovet JM, Zucman-Rossi J: Exome sequencing of hepatocellular carcinomas identifies new mutational signatures and potential therapeutic targets. Nat Genet 2015;47:505-511.

5 Totoki Y, Tatsuno K, Covington KR, Ueda H, Creighton CJ, Kato M, Tsuji S, Donehower LA, Slagle BL, Nakamura H, Yamamoto S, Shinbrot E, Hama N, Lehmkuhl M, Hosoda F, Arai Y, Walker K, Dahdouli M, Gotoh K, Nagae G, Gingras MC, Muzny DM, Ojima H, Shimada K, Midorikawa Y, Goss JA, Cotton R, Hayashi A, Shibahara J, Ishikawa S, Guiteau J, Tanaka M, Urushidate T, Ohashi S, Okada N, Doddapaneni H, Wang M, Zhu Y, Dinh H, Okusaka T, Kokudo N, Kosuge T, Takayama T, Fukayama M, Gibbs RA, Wheeler DA, Aburatani H, Shibata T: Trans-ancestry mutational landscape of hepatocellular carcinoma genomes. Nat Genet 2014;46:1267-1273.

6 Shibata T, Aburatani H: Exploration of liver cancer genomes. Nat Rev Gastroenterol Hepatol 2014;11:340349.

7 Cleary SP, Jeck WR, Zhao X, Chen K, Selitsky SR, Savich GL, Tan TX, Wu MC, Getz G, Lawrence MS, Parker JS, Li J, Powers S, Kim H, Fischer S, Guindi M, Ghanekar A, Chiang DY: Identification of driver genes in hepatocellular carcinoma by exome sequencing. Hepatology 2013;58:1693-1702.

8 Fujimoto A, Totoki Y, Abe T, Boroevich KA, Hosoda F, Nguyen HH, Aoki M, Hosono N, Kubo M, Miya F, Arai Y, Takahashi H, Shirakihara T, Nagasaki M, Shibuya T, Nakano K, Watanabe-Makino K, Tanaka H, Nakamura H, Kusuda J, Ojima H, Shimada K, Okusaka T, Ueno M, Shigekawa Y, Kawakami Y, Arihiro K, Ohdan H, Gotoh K, Ishikawa O, Ariizumi S, Yamamoto M, Yamada T, Chayama K, Kosuge T, Yamaue H, Kamatani N, Miyano S, Nakagama H, Nakamura Y, Tsunoda T, Shibata T, Nakagawa H: Whole-genome sequencing of liver cancers identifies etiological influences on mutation patterns and recurrent mutations in chromatin regulators. Nat Genet 2012;44:760-764.

9 Guichard C, Amaddeo G, Imbeaud S, Ladeiro Y, Pelletier L, Maad IB, Calderaro J, Bioulac-Sage P, Letexier M, Degos F, Clément B, Balabaud C, Chevet E, Laurent A, Couchy G, Letouzé E, Calvo F, Zucman-Rossi J: Integrated analysis of somatic mutations and focal copy-number changes identifies key genes and pathways in hepatocellular carcinoma. Nat Genet 2012;44:694-698.

10 Huang J, Deng Q, Wang Q, Li KY, Dai JH, Li N, Zhu ZD, Zhou B, Liu XY, Liu RF, Fei QL, Chen H, Cai B, Zhou B, Xiao HS, Qin LX, Han ZG: Exome sequencing of hepatitis B virus-associated hepatocellular carcinoma. Nat Genet 2012;44:1117-1121. 
11 Jhunjhunwala S, Jiang Z, Stawiski EW, Gnad F, Liu J, Mayba O, Du P, Diao J, Johnson S, Wong KF, Gao Z, Li Y, Wu TD, Kapadia SB, Modrusan Z, French DM, Luk JM, Seshagiri S, Zhang Z: Diverse modes of genomic alteration in hepatocellular carcinoma. Genome Biol 2014;15:436.

12 Li M, Zhao H, Zhang X, Wood LD, Anders RA, Choti MA, Pawlik TM, Daniel HD, Kannangai R, Offerhaus GJ, Velculescu VE, Wang L, Zhou S, Vogelstein B, Hruban RH, Papadopoulos N, Cai J, Torbenson MS, Kinzler KW: Inactivating mutations of the chromatin remodeling gene ARID2 in hepatocellular carcinoma. Nat Genet 2011;43:828-829.

13 Totoki Y, Tatsuno K, Yamamoto S, Arai Y, Hosoda F, Ishikawa S, Tsutsumi S, Sonoda K, Totsuka H, Shirakihara T, Sakamoto H, Wang L, Ojima H, Shimada K, Kosuge T, Okusaka T, Kato K, Kusuda J, Yoshida T, Aburatani $\mathrm{H}$, Shibata T: High-resolution characterization of a hepatocellular carcinoma genome. Nat Genet 2011;43:464-469.

14 Horn S, Figl A, Rachakonda PS, Fischer C, Sucker A, Gast A, Kadel S, Moll I, Nagore E, Hemminki K, Schadendorf D, Kumar R: TERT promoter mutations in familial and sporadic melanoma. Science 2013;339:959-961.

15 Killela PJ, Reitman ZJ, Jiao Y, Bettegowda C, Agrawal N, Diaz LA Jr, Friedman AH, Friedman H, Gallia GL, Giovanella BC, Grollman AP, He TC, He Y, Hruban RH, Jallo GI, Mandahl N, Meeker AK, Mertens F, Netto GJ, Rasheed BA, Riggins GJ, Rosenquist TA, Schiffman M, Shih IM, Theodorescu D, Torbenson MS, Velculescu VE, Wang TL, Wentzensen N, Wood LD, Zhang M, McLendon RE, Bigner DD, Kinzler KW, Vogelstein B, Papadopoulos N, Yan H: TERT promoter mutations occur frequently in gliomas and a subset of tumors derived from cells with low rates of self-renewal. Proc Natl Acad Sci USA 2013;110:6021-6026.

16 Nault JC, Mallet M, Pilati C, Calderaro J, Bioulac-Sage P, Laurent C, Laurent A, Cherqui D, Balabaud C, Zucman-Rossi J: High frequency of telomerase reverse-transcriptase promoter somatic mutations in hepatocellular carcinoma and preneoplastic lesions. Nat Commun 2013;4:2218.

17 Nault JC, Calderaro J, Di Tommaso L, Balabaud C, Zafrani ES, Bioulac-Sage P, Roncalli M, Zucman-Rossi J: Telomerase reverse transcriptase promoter mutation is an early somatic genetic alteration in the transformation of premalignant nodules in hepatocellular carcinoma on cirrhosis. Hepatology 2014;60:1983-1992.

18 El-Serag HB: Hepatocellular carcinoma. N Engl J Med 2011;365:1118-1127.

19 Kremsdorf D, Soussan P, Paterlini-Brechot P, Brechot C: Hepatitis B virus-related hepatocellular carcinoma: paradigms for viral-related human carcinogenesis. Oncogene 2006;25:3823-3833.

20 Ding D, Lou X, Hua D, Yu W, Li L, Wang J, Gao F, Zhao N, Ren G, Li L, Lin B: Recurrent targeted genes of hepatitis $B$ virus in the liver cancer genomes identified by a next-generation sequencing-based approach. PLoS Genet 2012;8:e1003065.

21 Ho DW, Sze KM, Ng IO: Virus-Clip: a fast and memory-efficient viral integration site detection tool at singlebase resolution with annotation capability. Oncotarget 2015;6:20959-20963.

22 Jiang Z, Jhunjhunwala S, Liu J, Haverty PM, Kennemer MI, Guan Y, Lee W, Carnevali P, Stinson J, Johnson S, Diao J, Yeung S, Jubb A, Ye W, Wu TD, Kapadia SB, de Sauvage FJ, Gentleman RC, Stern HM, Seshagiri S, Pant KP, Modrusan Z, Ballinger DG, Zhang Z: The effects of hepatitis B virus integration into the genomes of hepatocellular carcinoma patients. Genome Res 2012;22:593-601.

23 Lau C-C, Sun T, Ching AKK, He M, Li J-W, Wong AM, Co NN, Chan AW, Li PS, Lung RW, Tong JH, Lai PB, Chan HL, To KF, Chan TF, Wong N: Viral-human chimeric transcript predisposes risk to liver cancer development and progression. Cancer Cell 2014;25:335-349.

24 Li W, Zeng X, Lee NP, Liu X, Chen S, Guo B, Yi S, Zhuang X, Chen F, Wang G, Poon RT, Fan ST, Mao M, Li Y, Li S, Wang J, Jianwang, Xu X, Jiang H, Zhang X: HIVID: an efficient method to detect HBV integration using low coverage sequencing. Genomics 2013;102:338-344.

25 Sung WK, Zheng H, Li S, Chen R, Liu X, Li Y, Lee NP, Lee WH, Ariyaratne PN, Tennakoon C, Mulawadi FH, Wong KF, Liu AM, Poon RT, Fan ST, Chan KL, Gong Z, Hu Y, Lin Z, Wang G, Zhang Q, Barber TD, Chou WC, Aggarwal A, Hao K, Zhou W, Zhang C, Hardwick J, Buser C, Xu J, Kan Z, Dai H, Mao M, Reinhard C, Wang J, Luk JM: Genome-wide survey of recurrent HBV integration in hepatocellular carcinoma. Nat Genet 2012;44:765-769.

26 Liu M, Jiang L, Guan XY: The genetic and epigenetic alterations in human hepatocellular carcinoma: a recent update. Protein Cell 2014;5:673-691.

27 Ma L, Chua MS, Andrisani O, So S: Epigenetics in hepatocellular carcinoma: an update and future therapy perspectives. World J Gastroenterol 2014;20:333-345.

28 Saito Y, Hibino S, Saito H: Alterations of epigenetics and microRNA in hepatocellular carcinoma. Hepatol Res 2014;44:31-42.

29 Takahashi K, Yan I, Haga H, Patel T: Long noncoding RNA in liver diseases. Hepatology 2014;60:744-753.

30 Gao F, Liang H, Lu H, Wang J, Xia M, Yuan Z, Yao Y, Wang T, Tan X, Laurence A, Xu H, Yu J, Xiao W, Chen W, Zhou M, Zhang X, Chen Q, Chen X: Global analysis of DNA methylation in hepatocellular carcinoma by a liquid hybridization capture-based bisulfite sequencing approach. Clin Epigenetics 2015;7:86.

31 Tsang FH, Au SL, Wei L, Fan DN, Lee JM, Wong CC, Ng IO, Wong CM: Long non-coding RNA HOTTIP is frequently up-regulated in hepatocellular carcinoma and is targeted by tumour suppressive miR-125b. Liver Int 2015;35:1597-1606.

32 Ho DW, Kai AK, Ng IO: TCGA whole-transcriptome sequencing data reveals significantly dysregulated genes and signaling pathways in hepatocellular carcinoma. Fr Medicine 2015;9:322-330.

33 Huang Q, Lin B, Liu H, Ma X, Mo F, Yu W, Li L, Li H, Tian T, Wu D, Shen F, Xing J, Chen ZN: RNA-Seq analyses generate comprehensive transcriptomic landscape and reveal complex transcript patterns in hepatocellular carcinoma. PLoS ONE 2011;6:e26168.

34 Lin KT, Shann YJ, Chau GY, Hsu CN, Huang CY: Identification of latent biomarkers in hepatocellular carcinoma by ultra-deep whole-transcriptome sequencing. Oncogene 2014;33:4786-4794. 
35 Moeini A, Cornellà H, Villanueva A: Emerging signaling pathways in hepatocellular carcinoma. Liver Cancer 2012;1:83-93.

36 Whittaker S, Marais R, Zhu AX: The role of signaling pathways in the development and treatment of hepatocellular carcinoma. Oncogene 2010;29:4989-5005.

37 Wu X, Li Y: Signaling Pathways in Liver Cancer. in Julianov A, editor. Liver Tumors: Intech; 2012;37-58.

38 Zhai B, Hu F, Jiang X, Xu J, Zhao D, Liu B, Pan S, Dong X, Tan G, Wei Z, Qiao H, Jiang H, Sun X: Inhibition of Akt reverses the acquired resistance to sorafenib by switching protective autophagy to autophagic cell death in hepatocellular carcinoma. Mol Cancer Ther 2014;13:1589-1598.

39 Xia H, Ooi LL, Hui KM: MicroRNA-216a/217-induced epithelial-mesenchymal transition targets PTEN and SMAD7 to promote drug resistance and recurrence of liver cancer. Hepatology 2013;58:629-641.

40 Lo J, Lau EY, Ching RH, Cheng BY, Ma MK, Ng IO, Lee TK: Nuclear factor kappa B-mediated CD47 up-regulation promotes sorafenib resistance and its blockade synergizes the effect of sorafenib in hepatocellular carcinoma in mice. Hepatology 2015;62:534-545.

41 Rudalska R, Dauch D, Longerich T, McJunkin K, Wuestefeld T, Kang TW, Hohmeyer A, Pesic M, Leibold J, von Thun A, Schirmacher P, Zuber J, Weiss KH, Powers S, Malek NP, Eilers M, Sipos B, Lowe SW, Geffers R, Laufer S, Zender L: In vivo RNAi screening identifies a mechanism of sorafenib resistance in liver cancer. Nat Med 2014;20:1138-1146.

42 Hanahan D, Weinberg RA. Hallmarks of Cancer: The Next Generation. Cell 2011;1445:646-674.

43 Kroemer G, Pouyssegur J: Tumor cell metabolism: cancer's Achilles' heel. Cancer Cell 2008;13:472-482.

$44 \mathrm{Lu} \mathrm{X}$, Kang Y: Hypoxia and hypoxia-inducible factors: master regulators of metastasis. Clin Cancer Res 2010;16:5928-5935.

45 Cairns RA, Harris IS, Mak TW: Regulation of cancer cell metabolism. Nat Rev Cancer 2011;11:85-95.

46 Hamaguchi T, Iizuka N, Tsunedomi R, Hamamoto Y, Miyamoto T, Iida M, Tokuhisa Y, Sakamoto K, Takashima M, Tamesa T, Oka M: Glycolysis module activated by hypoxia-inducible factor 1alpha is related to the aggressive phenotype of hepatocellular carcinoma. Int J Oncol 2008;33:725-731.

47 Yasuda S, Arii S, Mori A, Isobe N, Yang W, Oe H, Fujimoto A, Yonenaga Y, Sakashita H, Imamura M: Hexokinase II and VEGF expression in liver tumors: correlation with hypoxia-inducible factor 1 alpha and its significance. J Hepatol 2004;40:117-123.

48 Semenza GL: HIF-1: upstream and downstream of cancer metabolism. Curr Opin Genet Dev 2010;20:51-56.

49 Denko NC: Hypoxia, HIF1 and glucose metabolism in the solid tumour. Nat Rev Cancer 2008;8:705-713.

50 Amann T, Maegdefrau U, Hartmann A, Agaimy A, Marienhagen J, Weiss TS, Stoeltzing 0, Warnecke C, Schölmerich J, Oefner PJ, Kreutz M, Bosserhoff AK, Hellerbrand C: GLUT1 expression is increased in hepatocellular carcinoma and promotes tumorigenesis. Am J Pathol 2009;174:1544-1552.

51 Amann T, Hellerbrand C: GLUT1 as a therapeutic target in hepatocellular carcinoma. Expert Opin Ther Targets 2009;13:1411-1427.

52 Dang CV, Kim JW, Gao P, Yustein J: The interplay between MYC and HIF in cancer. Nat Rev Cancer 2008;8:51-56.

53 Schwartzenberg-Bar-Yoseph F, Armoni M, Karnieli E: The tumor suppressor p53 down-regulates glucose transporters GLUT1 and GLUT4 gene expression. Cancer Res 2004;64:2627-2633.

54 Manning BD, Cantley LC: AKT/PKB signaling: navigating downstream. Cell 2007;129:1261-1274.

55 Chen Z, Lu X, Wang Z, Jin G, Wang Q, Chen D, Chen T, Li J, Fan J, Cong W, Gao Q, He X: Co-expression of PKM2 and TRIM35 predicts survival and recurrence in hepatocellular carcinoma. Oncotarget 2015;6:25382548.

56 Wong CC, Au SL, Tse AP, Xu IM, Lai RK, Chiu DK, Wei LL, Fan DN, Tsang FH, Lo RC, Wong CM, Ng IO: Switching of pyruvate kinase isoform L to M2 promotes metabolic reprogramming in hepatocarcinogenesis. PLoS ONE 2014;9:e115036.

57 Liu AM, Xu Z, Shek FH, Wong KF, Lee NP, Poon RT, Chen J, Luk JM: miR-122 targets pyruvate kinase M2 and affects metabolism of hepatocellular carcinoma. PLoS ONE 2014;9:e86872.

58 Iansante V, Choy PM, Fung SW, Liu Y, Chai JG, Dyson J, Del Rio A, D’Santos C, Williams R, Chokshi S, Anders RA, Bubici C, Papa S: PARP14 promotes the Warburg effect in hepatocellular carcinoma by inhibiting JNK1-dependent PKM2 phosphorylation and activation. Nat Commun 2015;6:7882.

59 Nie H, Li J, Yang XM, Cao QZ, Feng MX, Xue F, Wei L, Qin W, Gu J, Xia Q, Zhang ZG: Mineralocorticoid receptor suppresses cancer progression and the Warburg effect by modulating the miR-338-3p-PKLR axis in hepatocellular carcinoma. Hepatology 2015;62:1145-1159.

60 Wang C, Delogu S, Ho C, Lee SA, Gui B, Jiang L, Ladu S, Cigliano A, Dombrowski F, Evert M, Calvisi DF, Chen $\mathrm{X}$ : Inactivation of Spry2 accelerates AKT-driven hepatocarcinogenesis via activation of MAPK and PKM2 pathways. J Hepatol 2012;57:577-583.

61 Leung CO, Wong CC, Fan DN, Kai AK, Tung EK, Xu IM, Ng IO, Lo RC: PIM1 regulates glycolysis and promotes tumor progression in hepatocellular carcinoma. Oncotarget 2015;6:10880-10892.

62 Clarke MF, Dick JE, Dirks PB, Eaves CJ, Jamieson CH, Jones DL, Visvader J, Weissman IL, Wahl GM: Cancer stem cells-perspectives on current status and future directions: AACR Workshop on cancer stem cells. Cancer Res 2006;66:9339-9344.

63 Clevers H: The cancer stem cell: premises, promises and challenges. Nat Med 2011;17:313-319.

64 Holczbauer A, Factor VM, Andersen JB, Marquardt JU, Kleiner DE, Raggi C, Kitade M, Seo D, Akita H, Durkin ME, Thorgeirsson SS: Modeling pathogenesis of primary liver cancer in lineage-specific mouse cell types. Gastroenterology 2013;145:221-231.

65 Chan LH, Luk ST, Ma S: Turning hepatic cancer stem cells inside out-a deeper understanding through multiple perspectives. Mol Cells 2015;38:202-209. 
66 Lee TK, Cheung VC, Ng IO: Liver tumor-initiating cells as a therapeutic target for hepatocellular carcinoma. Cancer Lett 2013;338:101-109.

67 Ma S, Lee TK, Zheng BJ, Chan KW, Guan XY: CD133+ HCC cancer stem cells confer chemoresistance by preferential expression of the Akt/PKB survival pathway. Oncogene 2008;27:1749-1758.

68 Guan DX, Shi J, Zhang Y, Zhao JS, Long LY, Chen TW,Zhang EB, Feng YY, Bao WD, Deng YZ, Qiu L, Zhang XL, Koeffler HP, Cheng SQ, Li JJ, Xie D : Sorafenib enriches EpCAM positive tumor initiating cells and exacerbates a subtype of hepatocellular carcinoma through TSC2-AKT cascade. Hepatology 2015;62:1791-803

69 Decaens T, Godard C, de Reyniès A, Rickman DS, Tronche F, Couty JP, Perret C, Colnot S: Stabilization of betacatenin affects mouse embryonic liver growth and hepatoblast fate. Hepatology 2008;47:247-258.

70 Monga SP, Monga HK, Tan X, Mulé K, Pediaditakis P, Michalopoulos GK: Beta-catenin antisense studies in embryonic liver cultures: role in proliferation, apoptosis, and lineage specification. Gastroenterology 2003;124:202-216.

71 Mishra L, Banker T, Murray J, Byers S, Thenappan A, He AR, Shetty K, Johnson L, Reddy EP: Liver stem cells and hepatocellular carcinoma. Hepatology 2009;49:318-329.

72 Mokkapati S, Niopek K, Huang L, Cunniff KJ, Ruteshouser EC, deCaestecker M, Finegold MJ, Huff V: $\beta$-catenin activation in a novel liver progenitor cell type is sufficient to cause hepatocellular carcinoma and hepatoblastoma. Cancer Res 2014;74:4515-4525.

73 Yamashita T, Budhu A, Forgues M, Wang XW: Activation of hepatic stem cell marker EpCAM by Wnt-betacatenin signaling in hepatocellular carcinoma. Cancer Res 2007;67:10831-10839.

74 Yang W, Yan HX, Chen L, Liu Q, He YQ, Yu LX, Zhang SH, Huang DD, Tang L, Kong XN, Chen C, Liu SQ, Wu MC, Wang HY: Wnt/beta-catenin signaling contributes to activation of normal and tumorigenic liver progenitor cells. Cancer Res 2008;68:4287-4295.

75 Lee TK, Castilho A, Cheung VC, Tang KH, Ma S, Ng IO: CD24(+) liver tumor-initiating cells drive self-renewal and tumor initiation through STAT3-mediated NANOG regulation. Cell Stem Cell 2011;9:50-63.

76 Liu AY, Cai Y, Mao Y, Lin Y, Zheng H, Wu T, Huang Y, Fang X, Lin S, Feng Q, Huang Z, Yang T, Luo Q, Ouyang G: Twist2 promotes self-renewal of liver cancer stem-like cells by regulating CD24. Carcinogenesis 2014;35:537-545.

77 Won C, Kim BH, Yi EH, Choi KJ, Kim EK, Jeong JM, Lee JH, Jang JJ, Yoon JH, Jeong WI, Park IC, Kim TW, Bae SS, Factor VM, Ma S, Thorgeirsson SS, Lee YH, Ye SK: Signal transducer and activator of transcription 3-mediated CD133 up-regulation contributes to promotion of hepatocellular carcinoma. Hepatology 2015;62:1160-1173.

78 Liu C, Liu L, Shan J, Shen J, Xu Y, Zhang Q, Yang Z, Wu L, Xia F, Bie P, Cui Y, Zhang X, Bian X, Qian C: Histone deacetylase 3 participates in self-renewal of liver cancer stem cells through histone modification. Cancer Lett 2013;339:60-69.

79 Raggi C, Factor VM, Seo D, Holczbauer A, Gillen MC, Marquardt JU, Andersen JB, Durkin M, Thorgeirsson SS: Epigenetic reprogramming modulates malignant properties of human liver cancer. Hepatology 2014;59:2251-2262.

80 Raggi C, Invernizzi P: Methylation and liver cancer. Clin Res Hepatol Gastroenterol 2013;37:564-571.

81 You H, Ding W, Rountree CB: Epigenetic regulation of cancer stem cell marker CD133 by transforming growth factor-beta. Hepatology 2010;51:1635-1644.

82 Marquardt JU, Raggi C, Andersen JB, Seo D, Avital I, Geller D, Lee YH, Kitade M, Holczbauer A, Gillen MC, Conner EA, Factor VM, Thorgeirsson SS: Human hepatic cancer stem cells are characterized by common stemness traits and diverse oncogenic pathways. Hepatology 2011;54:1031-1042.

83 Chai S, Tong M, Ng KY, Kwan PS, Chan YP, Fung TM, Lee TK, Wong N, Xie D, Yuan YF, Guan XY, Ma S: Regulatory role of miR-142-3p on the functional hepatic cancer stem cell marker CD133. Oncotarget 2014;5:5725-5735.

84 Ji J, Yamashita T, Budhu A, Forgues M, Jia HL, Li C, Deng C, Wauthier E, Reid LM, Ye QH, Qin LX, Yang W, Wang HY, Tang ZY, Croce CM, Wang XW: Identification of microRNA-181 by genome-wide screening as a critical player in EpCAM-positive hepatic cancer stem cells. Hepatology 2009;50:472-480.

85 Yamashita T, Wang XW: Cancer stem cells in the development of liver cancer. J Clin Invest 2013;123:1911-1918

86 Schrader J, Gordon-Walker TT, Aucott RL, van Deemter M, Quaas A, Walsh S, Benten D, Forbes SJ, Wells RG, Iredale JP: Matrix stiffness modulates proliferation, chemotherapeutic response, and dormancy in hepatocellular carcinoma cells. Hepatology 2011;53:1192-1205.

87 Wan S, Zhao E, Kryczek I, Vatan L, Sadovskaya A, Ludema G, Simeone DM, Zou W, Welling TH: Tumor-associated macrophages produce interleukin 6 and signal via STAT3 to promote expansion of human hepatocellular carcinoma stem cells. Gastroenterology 2014;147:1393-1404.

88 Luedde T, Schwabe RF: NF- $\kappa$ B in the liver-linking injury, fibrosis and hepatocellular carcinoma. Nat Rev Gastroenterol Hepatol 2011;8:108-118.

89 Marquardt JU, Gomez-Quiroz L, Arreguin Camacho LO, Pinna F, Lee YH, Kitade M, Domínguez MP, Castven D, Breuhahn K, Conner EA, Galle PR, Andersen JB, Factor VM, Thorgeirsson SS: Curcumin effectively inhibits oncogenic NF- $\kappa B$ signaling and restrains stemness features in liver cancer. J Hepatol 2015;63:661-669.

90 Huch M, Dorrell C, Boj SF, van Es JH, Li VS, van de Wetering M, Sato T, Hamer K, Sasaki N, Finegold MJ, Haft A, Vries RG, Grompe M, Clevers H: In vitro expansion of single Lgr5+ liver stem cells induced by Wnt-driven regeneration. Nature 2013;494:247-250.

91 Lo J, Lau EY, So FT, Lu P, Chan VS, Cheung VC, Ching RH, Cheng BY, Ma MK, Ng IO, Lee TK: Anti-CD47 antibody suppresses tumour growth and augments the effect of chemotherapy treatment in hepatocellular carcinoma. Liver Int 2015. doi: 10.1111/liv.12963 